\title{
Antibody-dependent CD56+ $T$ cell responses are functionally impaired in long-term HIV-1 infection
}

\author{
Xueying Fan ${ }^{1 \dagger}$, Liyan Zhu ${ }^{1 \dagger}$, Hua Liang ${ }^{2}$, Zhe Xie ${ }^{1}$, Xiangbo Huang ${ }^{1}$, Shuo Wang ${ }^{2}$ and Tao Shen ${ }^{1 *}$
}

\begin{abstract}
Background: Antibody-dependent cellular cytotoxicity (ADCC), which mainly mediated by natural killer (NK) cells, may play a critical role in slowing human immunodeficiency virus type-1 (HIV-1) disease progression and protecting from HIV-1 infection. Besides classic NK cells, CD56+ T cells also have some NK cell-like properties, such as the large granular lymphocyte morphology and the capacity to destroy NK-sensitive target cells. However, little is known about the potentials of antibody-dependent CD56+ T cell responses and the association between antibody-dependent CD56+ T cell responses and HIV-1 disease progression.

Results: In the present study, we showed evidences that, in addition to NK cells, CD56+T cells could generate degranulation upon CD16 cross-linking. Ex vivo study showed that FcyRIII (CD16)-mediated CD56+ T cell responses were distinctly induced by lgG antibody-bound P815 cells. Comparatively, CD56- T cells and invariant NKT (CD3+ $6 \mathrm{~B} 11+$ ) failed to induce antibody-dependent activation. Antibody-dependent CD56+ T cell responses were mainly ascribed to CD4/CD8 double negative subset and were functionally impaired in long-term HIV-1-infected former plasma donors, regardless of hepatitis C virus (HCV) coinfection status. Also, CD56+ T cell-mediated HIV-1-specific antibody-dependent responses were declined in men who have sex with men with HIV-1 infection over 3 years. Finally, we showed that matrix metalloprotease (MMP) inhibitor GM6001 could partially restored antibody-dependent CD56+ T cell responses of chronic HIV-1-infected subjects.
\end{abstract}

Conclusions: Our results suggested that CD56+T cells could mediate ADCC responses and the responses were impaired in chronic HIV-1 infection.

Keywords: CD56+ T, ADCC, CD16 cross-linking, Chronic HIV infection, iNKT, MMP inhibitor

\section{Background}

Antibody-dependent cellular cytotoxicity (ADCC) is a combined immune responses involving both innate and adaptive immunity [1]. In human, ADCC is typically initiated by recognition of membrane-surface antigens FcyRIIIa (CD16) or FcyRIIc (CD32) of effector cells to the Fc region of IgG antibodies which binding to specific antigens on the surface of target cells $[2,3]$. In the

\footnotetext{
*Correspondence: taoshen@hsc.pku.edu.cn

${ }^{+}$Xueying Fan and Liyan Zhu contributed equally to this work

1 Department of Microbiology and Center of Infectious Diseases, Peking

University Health Science Center, 38 Xueyuan Road, Haidian District,

Beijing 100191, China

Full list of author information is available at the end of the article
}

last decade, substantial evidences supported the crucial role of ADCC activities in controlling HIV infection. For example, HIV-specific ADCC responses were reported detectable in all tested elite controllers and was significantly higher than in HIV viremic individuals, and ADCC activities were correlated with slowed progression to acquired immune deficiency syndrome (AIDS) in SIV-infected macaques [4-6]. The well-known Thai RV144 HIV vaccine trail showed $31 \%$ protection in preventing HIV acquisition with induction of robust HIVspecific ADCC responses [7-9]. In addition to NK cells, other types of circulating granulocytes, such as neutrophils, monocytes and macrophages, were also reported to mediate ADCC activity [10-14]. 
CD56+ T cells, also termed CD3+ CD56+ NKT-like cells, comprise approximately $5-15 \%$ of peripheral circulating $\mathrm{T}$ cells in human and express cell-surface moleculeCD56, a typical marker for natural killer (NK) cells [15]. CD56+ $\mathrm{T}$ cells are also characterized by some NK celllike properties, such as the large granular lymphocyte morphology and the capacity to destroy NK-sensitive target cells $[15,16]$. Compared with CD56+ T cells, the CD1d-restricted invariant NKT (iNKT) cells, which are characterized by expression of a specific $\mathrm{T}$ cell receptor (TCR) (V $\alpha 24-J \alpha 18-V \beta 11$ in humans), also play an important regulatory role in the innate and adaptive immune responses. These iNKT cells share partially phenotypic and functional properties with NK and CD56+ T cells [17]. CD56+ $\mathrm{T}$ cells were presumed to display properties of both NK cells and T cells and exhibited capacities of cytotoxicity and cytokine production in both MHCrestricted and MHC-unrestricted manner. CD56+ T cells displayed an essential role in antiviral immune response, such as inhibiting HCV and HIV-1 replication in vitro $[18,19]$. However, little is known about the potentials of CD56+ $\mathrm{T}$ cells in mediating ADCC responses and the association between CD56+ T cell-mediated ADCC responses and HIV-1 disease progression.

In this study, ex vivo ADCC activities mediated by CD56+ $\mathrm{T}$ cells were investigated in healthy versus chronic HIV-1 infected subjects and were compared with NK-mediated ADCC responses. Potenial factors that may influence ADCC activities, such as FcyR expression, CD56+ T subset distribution, and MMPs inhibitor, were also evaluated.

\section{Results}

\section{CD16 cross-linking triggered degranulation of CD56+ T cells}

FcyRIIIa (CD16), a low-affinity receptor, could bind to the Fc region of IgG and trigger ADCC responses. Besides CD16, FcyRIIc (CD32) was also reported responsible for ADCC effect [20,21]. In this study, the frequencies of CD16+ or CD32+ subsets in CD56+ $\mathrm{T}$ cells, CD3+ CD56+ NK cells and CD3+ CD56- T cells was identified and compared (Fig. 1a, b). As expected, a considerable percentage of CD56+ $\mathrm{T}$ cells was CD16+ CD56+ $\mathrm{T}$ cells $(11.4 \pm 8.1 \%)$, which was lower than the percentage on NK cells $(60.2 \pm 18.9 \%, P<0.001)$ but higher than on CD56- T cells $(0.9 \pm 0.5 \%, P<0.001)$. On the contrary, the percentage of CD32+ CD56+ T cells was found very low (less than $2 \%$ ) on all three cell populations (Fig. 1b). The expression of CD16 and CD32 was confirmed on single cell level by image analysis (Fig. 1c). Purified CD56+ T cells (Purity > 95\%, Additional file 1: Fig. S1) were triggered to degranulate after cross-linking with anti-CD16 monoclonal Ab, but not with anti-CD32
Ab $(P<0.001$, Fig. 1d, e). Taken together, these results indicated that CD56+ $\mathrm{T}$ cells expressed a considerable level of CD16 and could be triggered to degranulate after CD16 cross-linking.

\section{CD56+ T cells could mediate ADCC responses}

In order to extensively detect the capacity of CD56+ cells to mediate ADCC responses, peripheral blood mononuclear cells (PBMCs) were stimulated with P815 cells coated with P815-specific antibodies (P815/Abs) and ADCC response was reflected by $\mathrm{CD} 107 \mathrm{a}$ and interferon- $\gamma($ IFN $\gamma)$ production of CD56 $+\mathrm{T}, \mathrm{CD} 56+\mathrm{NK}$ and CD56- T cells. As shown in Fig. $2 a, b$, IFN- $\gamma$ and CD107a expression were dramatically elevated in P815/ Abs-stimulated CD56+ T and CD56+ NK cells compared with CD56- T cells $(P<0.001$ for all). In addition, CD56+ $\mathrm{T}$ cells expressed a significantly lower CD107a $(P<0.001)$ while similar level of IFN $\gamma$ when compared with CD56+ NK cells, indicating a weaker degranulation capacity of CD56+ T cells versus NK cells (Fig. 2b). In addition, ADCC response time between CD56+ $\mathrm{T}$ and CD56+ NK cells was compared by stimulating effector cells with P815/Abs for 2, 4 and $6 \mathrm{~h}$ respectively. As shown in Additional file 2: Fig. S2a and S2b, CD56+ T cells responded to antibody-dependent stimulation after $6 \mathrm{~h}$ incubation, while NK cells usually responded after $4 \mathrm{~h}$ incubation, which was more quickly than CD56+ T cells.

It is speculated that conjugation of CD16 with Abopsonized P815 cells led to down-regulation of CD16 expression and a subsequent cascade of intracellular signal activation, triggering IFN $\gamma$ and $\mathrm{CD} 107$ a production. In this study, we found that stimulation with Abopsonized P815 cells led to a tremendous decrease of CD16+ population in CD56+ $\mathrm{T}$ cells and NK cells, but not in CD56- T subset (Fig. 2c), which was in accordance with their capacities to mediate ADCC response. Further analysis revealed a significant correlation between MFI loss of CD16 and CD107a expression $(r=0.618$, $P<0.001)$ in CD56+ $\mathrm{T}$ cell-mediated ADCC responses (Fig. 2d). In P815/Abs activated CD56+ T cells, CD107a expression was positively correlated with IFN $\gamma$ secretion ( $\mathrm{r}=0.919, P<0.001$, Fig. 2e), indicating that cellular degranulation and IFN $\gamma$ production may share common signal activation pathway in ADCC activities mediated by CD56+ T cells.

To confirm the capacity of CD56+ $\mathrm{T}$ cells to mediate ADCC responses, purified CD56+ $\mathrm{T}$ cells were cocultured with P815 cells or Ab-opsonized P815 cells, and supernatants were collected for IFN $\gamma$ detection by ELISA. As shown in Fig. 2f, the levels of IFNY were significantly higher in cell supernatant stimulated with $\mathrm{Ab}$ coated p815 cells than with P815 cells alone $(P<0.001)$, confirming that peripheral CD56 $+\mathrm{T}$ cells possessed 


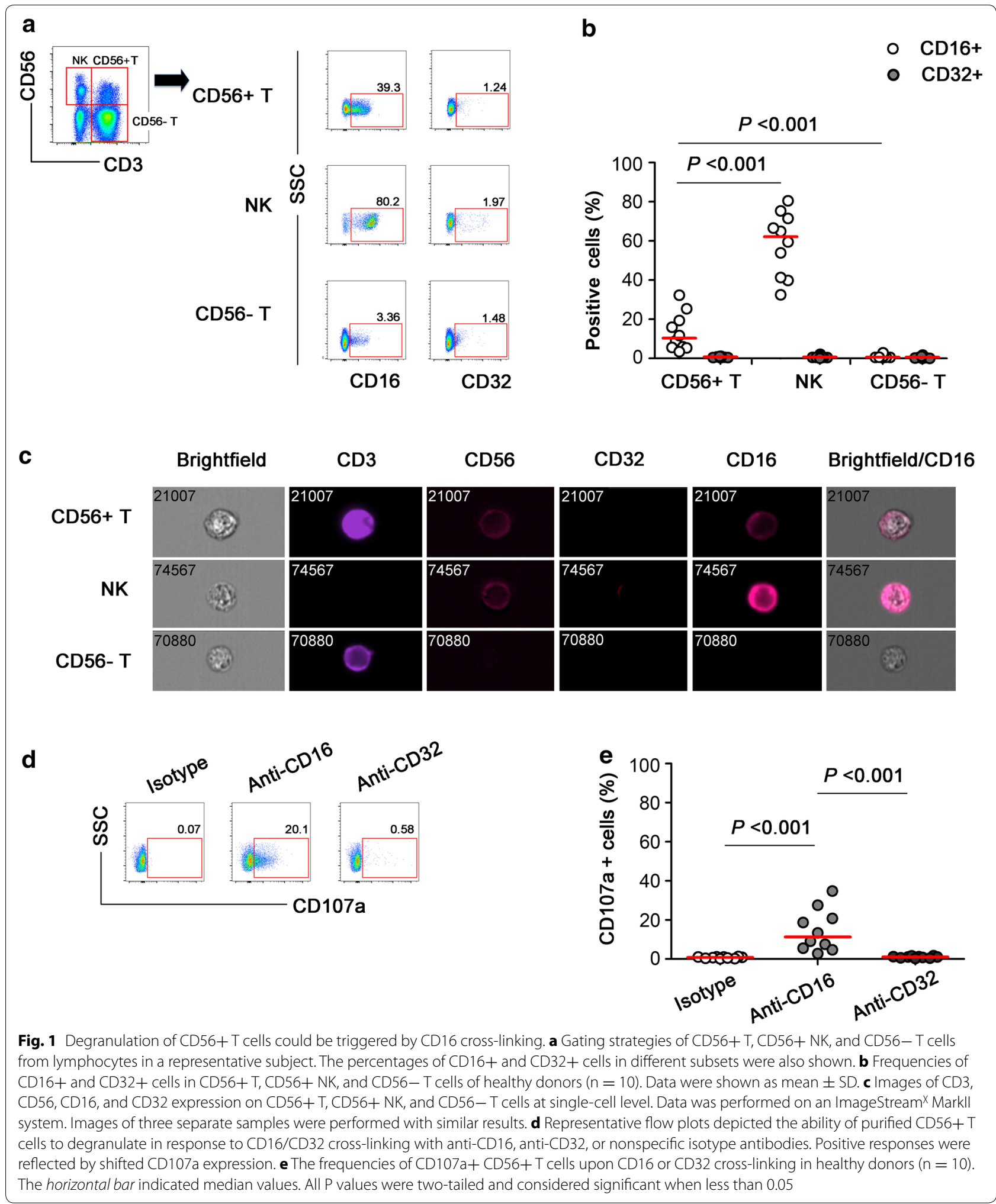

the potential to mediate ADCC function. Moreover, to address antibody-dependent lytic capacity of purified CD56+ T cell, target P815 cells were pre-stained with PKH26 and CFSE, and a rapid fluorometric ADCC (RFADCC) assay was employed to detect the frequencies of $\mathrm{CFSE}^{-/ \text {low }}$ target cells (Fig. 2g). As shown in Fig. 2h, 


\section{(See figure on next page.)}

Fig. 2 Nonspecific ADCC responses mediated by CD56+T,CD56+ NK and CD56- T cells. a Representative flow plots showing the capacities of CD56+ T,CD56+ NK and CD56- T cells to respond to P815 cells coated with P815-specific Abs (P815+ Ab), p815 cell alone, or medium. Positive ADCC responses were represented by increased CD107a expression and IFNy secretion. b Nonspecific ADCC activities mediated by CD56+ T, CD56+ NK and CD56 - T cells were evaluated in 36 healthy donors. The difference of percentage (P815/Ab minus P815) of CD107a+ and IFNy+ cells in CD56+ T,CD56+ NK and CD56- T cells stimulated by Ab-bound P815 cells was shown. The horizontal bar indicated median values. c MFI loss (P815 minus P815/Ab) of CD16 on CD56+T, CD56+ NK and CD56- T cells following stimulation with Ab-bound P815 cells. Horizontal bar indicated median value. $\mathbf{d}$ MFI loss of CD16 was correlated with CD107a + expression in CD56+ T cell-mediated nonspecific ADCC response. e CD107a expression was correlated with IFNy production in CD56+T cell-mediated nonspecific ADCC responses. f Purified CD56+T cells were co-cultured with P815 cells or Ab-bound P815 cells for $24 \mathrm{~h}$ and levels of IFNY in cell supernatants were detected by ELISA. g Representative flow plots showing lytic capacities of purified CD56+ T, NK, CD56-T cells co-cultured with P815 cells or Ab-bound P815 cells for $10 \mathrm{~h}$. Target P815 cells were shown as PKH26+ cells and CFSE ${ }^{-/ 10 w}$ target cells indicated lysed target cells. $\mathbf{h}$ The percentage of lysed target cells induced by CD56+ T, CD56+ NK and CD56- T cells in healthy donors $(n=10)$. All P values were two-tailed and considered significant when less than 0.05

the percentage of lysed P815 target cells were higher in CD56+ $\mathrm{T}$ cells incubating with Ab-coated p815 cells than with P815 cells alone $(P<0.001)$. A similar trend of antibody-dependent lytic capacity was found in NK cells but not in CD56- T cells. Taken together, these results indicated that ADCC responses could be mediated by $\mathrm{CD} 56+\mathrm{T}$ cells though the intensity was generally lower than the response mediated by classic CD56+ NK cells.

\section{Invariant NKT failed to mediate ADCC responses}

Peripheral iNKT is usually defined as CD3+ V $224-J \alpha 18+$ double positive cells in lymphocytes. Initially, we detected the frequencies of CD16+, CD161+ [22] and CD69+ [23] (two markers of lymphocyte activation) cells in iNKT cells and CD56+ T cells from 10 healthy donors. As indicated in Fig. 3a, b, compared to CD56+ $\mathrm{T}$ cells, a significantly lower frequency of CD16+ iNKT cells were found $(P=0.006)$. No differences of CD161+ and CD69+ cells were presented between these two types of cells. Furthermore, the capacity of iNKT to mediate ADCC was evaluated by detecting the frequency of IFN $\gamma+$ cells using the strategy for ADCC detection above. Compared to CD56+ T cells, IFN $\gamma$-producing iNKT cells were extremely lower after stimulating with Ab-bound P815 cells (Fig. 3c). There was no significant difference in IFN $\gamma$ production between iNKT cells stimulated with P815 cells alone and Ab-bound P815 cells $(P>0.05)$, in contrast to CD56+ T cells which showed an dramatically increased IFN $\gamma+$ production after stimulating with Ab-bound P815 cells $(P<0.001)$ (Fig. 3d). These data demonstrated that, unlike CD56+ $\mathrm{T}$ cells, iNKT cells were unable to mediate ADCC responses.

\section{CD56+ T cell-mediated nonspecific ADCC was impaired in long-term HIV-1 infected FPDs}

Nonspecific ADCC activity mediated by CD56+ T cells and CD56+ NK cells were evaluated in long-term HIV1 -infected former plasma donors (FPDs) ( $\mathrm{n}=76$, of which 36 were coinfected with HCV) and healthy controls $(\mathrm{n}=36)$. Compared to healthy controls, CD56+ T cell-mediated nonspecific ADCC responses were significantly lower in both HIV-1 monoinfected individuals $(P<0.001$ for CD107a, and $P=0.048$ for IFNY) and HIV-1/HCV coinfected individuals $(P<0.001$ for CD107a, and $\mathrm{P}=0.008$ for IFNY), which was similar to the trends of ADCC mediated by CD56+ NK cells $(P<0.001$ for all) (Fig. 4a, b). The decreased ADCC activities might be ascribed to the functional impairment of CD56+ T cells, since the frequencies of $\mathrm{CD} 56+\mathrm{T}$ cells were comparable among HIV-1 monoinfected subjects, HIV-1/HCV coinfected subjects, and healthy subjects $(P>0.05$, Fig. $4 \mathrm{c})$ and the frequency of CD16+ cells within CD56+ T-cells was even higher in HIV infected subjects than in healthy controls $(P=0.018$ for HIV-1 monoinfection and $P=0.003$ for $\mathrm{HIV}-1 / \mathrm{HCV}$ coinfection) (Fig. 4d). No differences were found between HIV-1 monoinfection and HIV-1/ $\mathrm{HCV}$ coinfection regarding to ADCC activities mediated by either CD56+ T or CD56+ NK cells, suggesting that $\mathrm{HCV}$ coinfection had no or negligible influence on nonspecific ADCC activities in HIV-1 infection.

In addition, the positive correlations between frequencies of CD107a+ CD56+ T cells and MFI loss of CD16 on CD56+ T cells still existed in both HIV-1-monoinfected $(\mathrm{r}=0.545, P=0.007)$ and HIV-1/HCV-coinfected $(\mathrm{r}=0.658, P<0.001)$ subjects (Fig. 4e). Similarly, positive correlations between frequencies of CD107a+ CD56+ T cells and IFN $\gamma+$ CD56 + T cells were presented in HIV-1 monoinfection $(\mathrm{r}=0.335, P=0.043)$ and HIV-1/HCV coinfection ( $\mathrm{r}=0.453, P=0.018$ ) (Fig. 4f). These results indicated that $\mathrm{CD} 56+\mathrm{T}$ cells sustained the balance of cytotoxicty and immune regulation, though with an impaired capacities to mediated immune responses. No significant correlation between CD56 $+\mathrm{T}$ cell-mediated ADCC activities and HIV-1 viral loads or CD4+ T cell counts were found (data not shown).

Taken together, these data suggested that HIV-1 infection impaired the capacity of nonspecific CD56+ $\mathrm{T}$ cells to mediate ADCC responses in long-term HIV-1+ subjects, while HCV coinfection did not aggravate the impairment. 


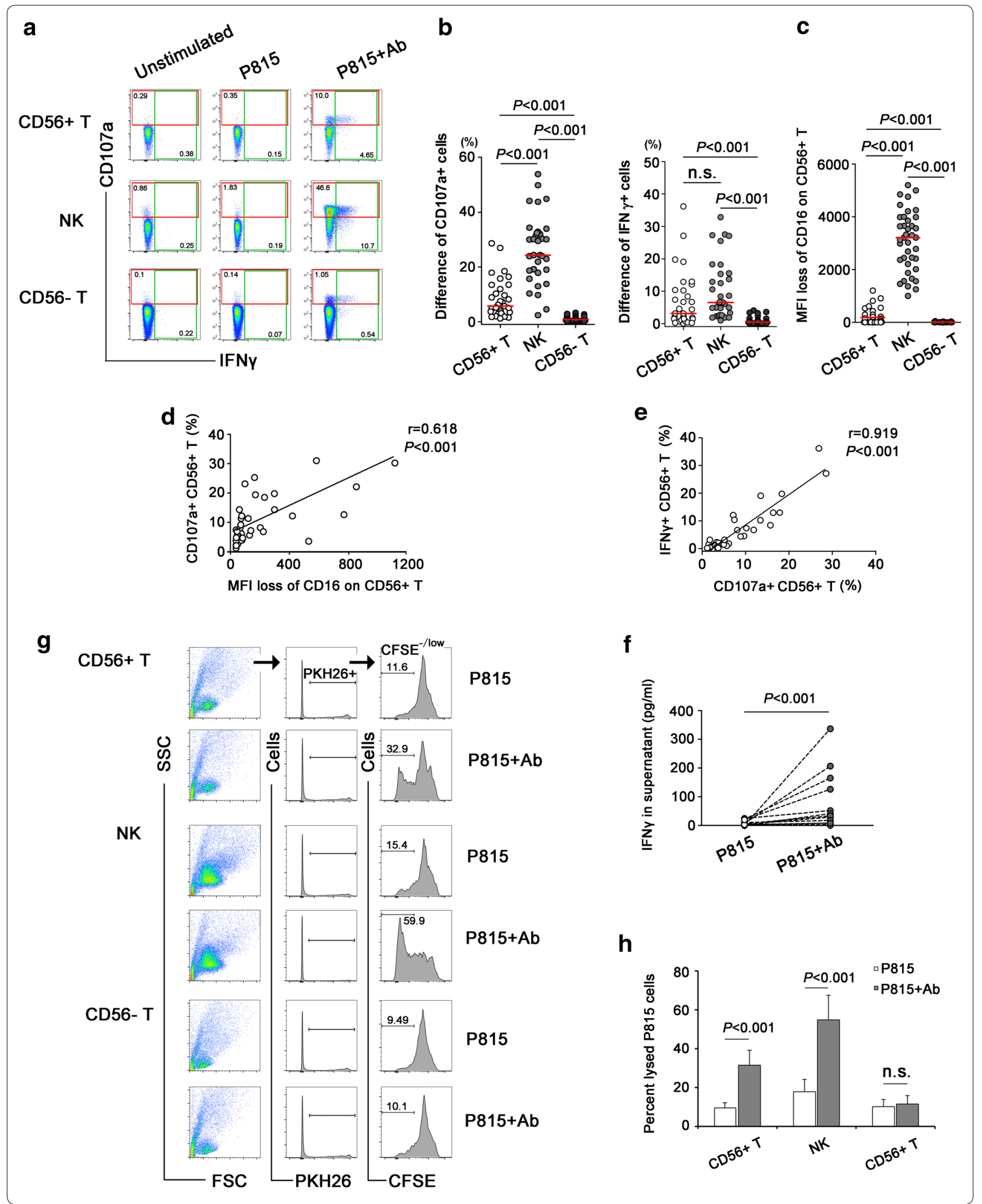


a

iNKT
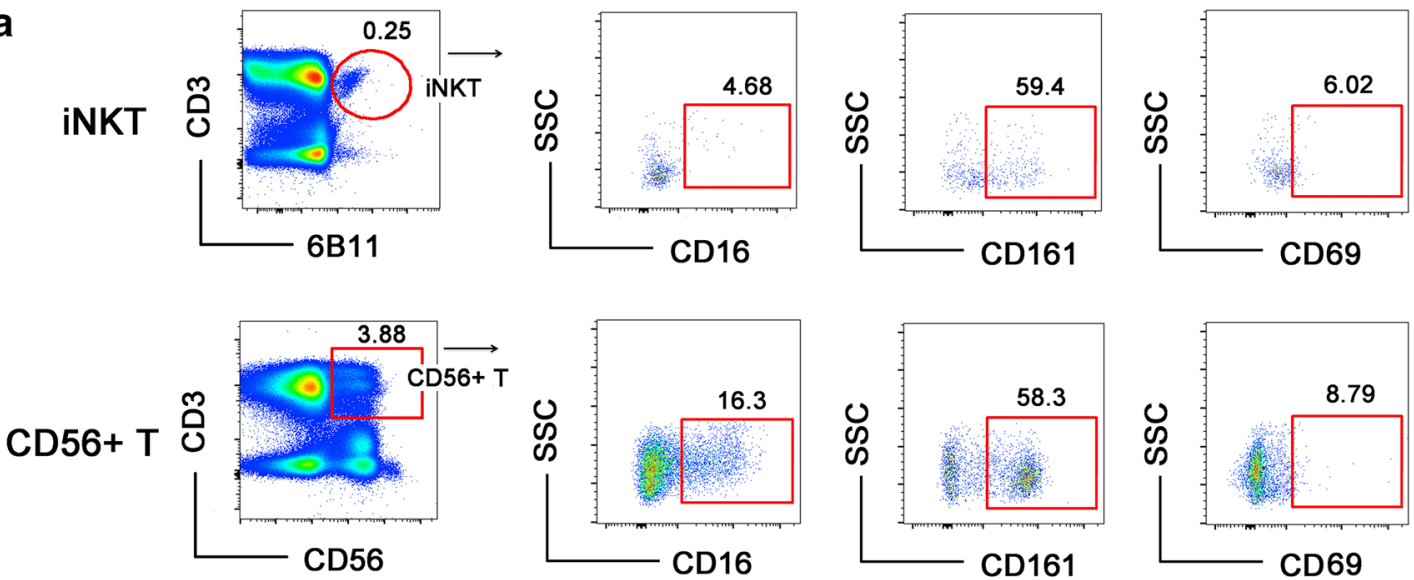

b

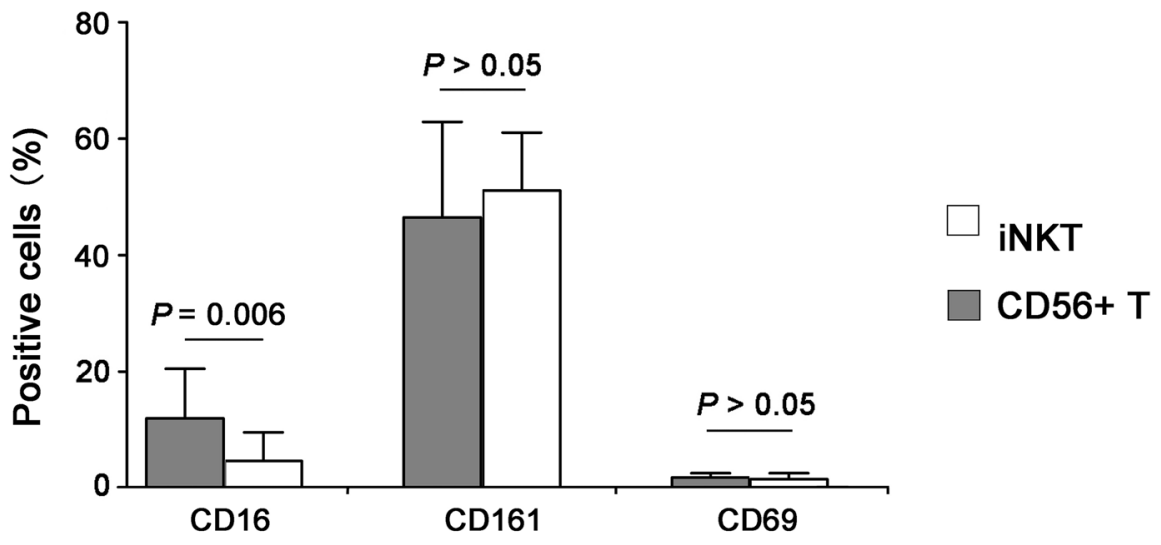

C

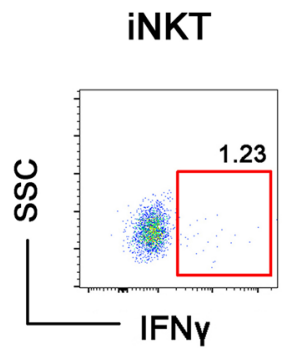

d

iNKT

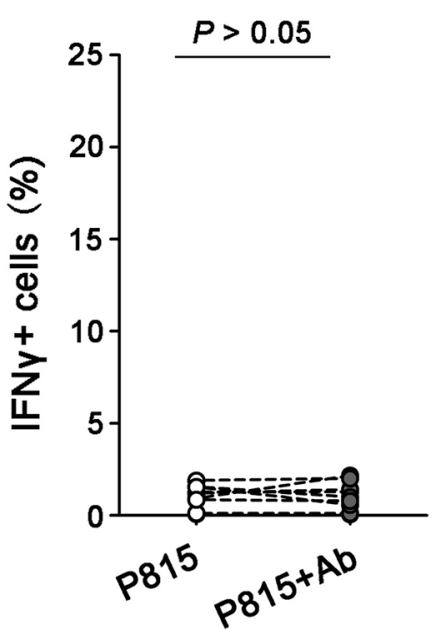

CD56+ T

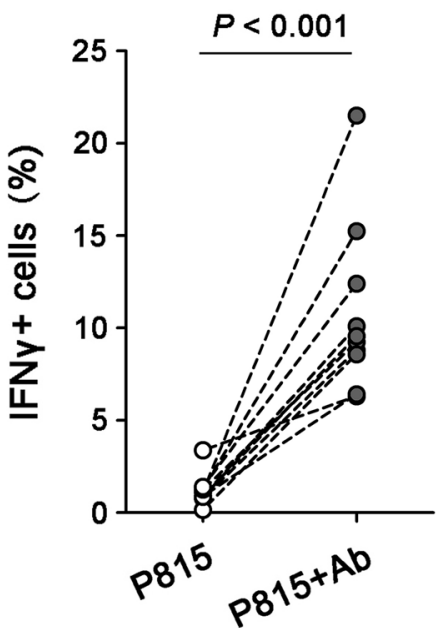

Fig. 3 Evaluation of nonspecific ADCC activity mediated by invariant NKT cells. a The representative flow plots indicated CD16, CD161 and CD69 expression on human invariant NKT cells (iNKT, CD3+6B11+) and CD56+ T cellsrespectively. b Comparison of CD16, CD161 and CD69 expression on iNKT and CD56+ T cells from ten healthy donors. c The representative flow plots indicated IFNy production by iNKT and CD56+ T cells stimulated by Ab-bound P815 cells. d The frequencies of IFNY + iNKT and IFNY + CD56+ T cells from ten healthy donors in response to P815 cells alone or Ab-coated P815 cells. All P values were two-tailed and considered significant when less than 0.05 


\section{(See figure on next page.)}

Fig. 4 Nonspecific ADCC activities mediated by CD56+T cells and CD56+ NK cells in long-term HIV-1-monoinfected FPDs, HIV-1/HCV-coinfected FPDs, and healthy donors. a Representative flow plots showed the levels of CD107a expression and IFNy production from CD56+T cells and CD56+ NK cells in HIV-1 infected subjects and healthy controls. b Comparison of percentages of CD107a+ (left panel) or IFNץ+ (right panel) cells in CD56+ T cells and CD56+ NK cells between HIV-1 infected subjects and healthy controls. c The frequencies of CD56+ T cells and CD56+ NK cells in peripheral lymphocytes in HIV-1 infected subjects and healthy controls. $\mathbf{d}$ The percentages of CD16+ cells in CD56+ T cells and CD56+ NK cells of HIV-1 infected subjects and healthy controls. e Correlations between the MFI loss of CD16 and expression of CD107a in CD56+ T cell-mediated nonspecific ADCC in HIV-1/HCV-coinfected (dash line) and HIV-1-monoinfected groups (solid line). f Correlations between CD107a expression and IFNy production in CD56+ T cell-mediated nonspecific ADCC in HIV-1/HCV-coinfected (dash line) and HIV-1-monoinfected groups (solid line). The horizontal bar indicated median values. All $P$ values were two-tailed and considered significant when lower than 0.05

\section{HIV-1-specific ADCC activities mediated by CD56+ T cells} were declined in MSM with HIV-1 infection over 3 years

HIV-1-specific ADCC activities were evaluated in men who have sex with men (MSM) subjects with HIV-1-infection for $1-3$ years $(n=22)$ and over 3 years $(n=13)$. HIV-specific ADCC responses were identified by the frequencies of $\mathrm{CD} 107 \mathrm{a}+$ or $\mathrm{IFN} \gamma+\mathrm{CD} 56+\mathrm{T}$ cells in response to HIV-1 specific peptide pools (Fig. 5a). In MSM with HIV-1-infection over 3 years, intracellular IFN $\gamma$ expression by CD56+ $\mathrm{T}$ cells was dramatically declined in comparison with in subjects infected for $1-3$ year (env: $P=0.028$, gag: $P=0.008$, and pol: $P=0.025$, Fig. 5c). Though similar trends were found in the frequency of CD107a+CD56+ T cells in response to individual peptide pool, no significant $P$ values were reached (Fig. 5b). These data indicated that CD56+ $\mathrm{T}$ cell-mediated ADCC was impaired in chronic HIV-1-infected subjects but not recently infected subjects, which was consistent with the impaired capacities of CD56+ $\mathrm{T}$ cells to mediate nonspecific ADCC responses in longtime HIV-1 infected FPDs.

\section{CD56+ T cells mediating ADCC activities were mainly CD4/ CD8 double negative subset}

According to the surface expression of CD4 and CD8, CD56+ $\mathrm{T}$ cells could be divided into three subsets: CD4+ CD8- (CD4+ subset), CD4- CD8+ (CD8+ subset), CD4-CD8- (double negative subset, DN) (Fig. 6a). In healthy subjects, the proportion of $\mathrm{DN}$ subset and CD8+ subset was similar, occupying appropriate $40 \%$ of total CD56+ $\mathrm{T}$ cells respectively, while the frequency of CD4+ subset was significantly lower than DN and CD8+ subsets $(P<0.001$, Fig. $6 \mathrm{~b})$. In long-term HIV-infected subjects, the frequency of CD4+ subset was significantly decreased $(P=0.007)$, while the frequency of CD8+ subset was increased $(P=0.023)$ when compared to healthy controls (Fig. 6b). No difference in percentage of DN subset was found between HIV-infected FPDs and healthy controls $(P>0.05$, Fig. 6b).

Next, ADCC activities mediated by different CD56+ $\mathrm{T}$ subsets were evaluated. As shown in Fig. $6 \mathrm{c}, \mathrm{d}, \mathrm{DN}$ subset contributed to the highest CD107a expression
(DN vs. $\mathrm{CD} 8+: P=0.004)$ and IFNY production (DN vs. $\mathrm{CD} 4+: P=0.028$; $\mathrm{DN}$ vs. $\mathrm{CD} 8+: P=0.004)$ in healthy controls, though CD16+ frequency was lower on DN subset compared with $\mathrm{CD} 4+$ subset $(P<0.001$, Fig. $6 \mathrm{e})$. In long-term HIV-1 infection, ADCC activities mediated by $\mathrm{DN}$ CD56+ $\mathrm{T}$ subset were significantly declined (CD107a: $P=0.018$; IFN $\gamma: P=0.010$ ), indicating a functional impairment of the subset (Fig. 6c, d). The favorable ADCC activities mediated by DN CD56+ T subset was confirmed by the most loss of CD16 (frequencies) on DN subset than CD8+ subsets in both HIV-1-infected subjects $(P=0.026)$ and healthy controls $(P=0.038)$ (Fig. 6f). Of note, for HIV-1 infection, the characteristics of CD4+ subset and its capacity to mediate ADCC responses were missed in the study due to a very low cells number resulting unreliable results. Taken together, these results suggested that ADCC response mediated by CD56+ T cells was mainly ascribed to DN subset and was significantly impaired in long-term HIV-1 infection.

Finally, in consideration of different performances of three subsets of CD56+ $\mathrm{T}$ in mediating ADCC activities, we evaluated the characteristics of CD56+ $\mathrm{T}$ subsets in expressing NK cell-associated markers, including NKG2A, NKG2C, NKG2D, NKp44 and NKp46. The data showed a good consistency that the highest levels of activate receptor NKG2C, NKG2D, NKp44 and NKp46 were observed on CD8+ subset, and moderate on DN cells and the lowest on CD4+ subset (Fig. 6g). However, inhibitory receptor NKG2A was found highest on DN subset $(P<0.001)$ (Fig. 6g).

\section{MMP inhibitor could partially restore CD56+ $T$ cells mediated ADCC in long-term HIV-1 infected subjects}

Activation of NK cells induces matrix metalloproteinase (MMP)-mediated cleavage of cell surface CD16 [24-26]. MMP inhibitor was reported to improve the ability of NK cells to mediate ADCC [27]. In this study, we found that CD16 MFI on DN CD16+ CD56+ T cells was lower in HIV+ patients versus healthy donors $(P=0.005)$ (Fig. 7a) and could be reversed by GM6001 treatment for 3,6 and $12 \mathrm{~h}(P<0.001$, Fig. $7 \mathrm{~b})$. To evaluate whether MMP inhibitor could improve CD56+ T cells mediated 
a

CD56+ $\mathrm{T}$

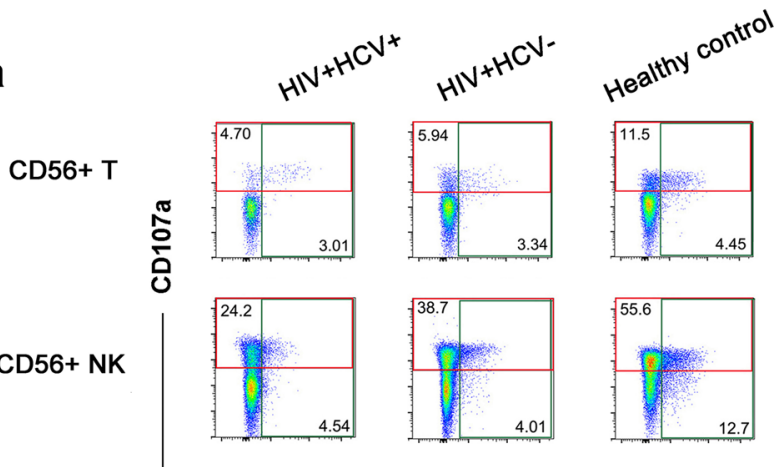

IFNY

b

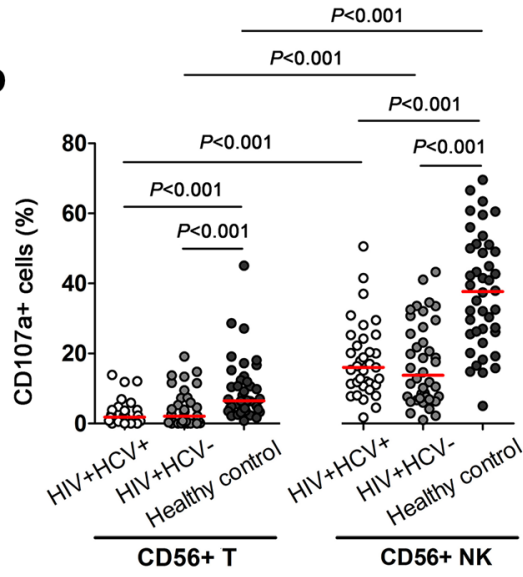

C

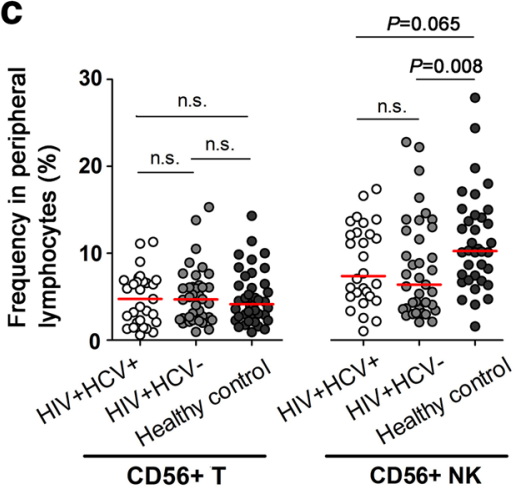

e

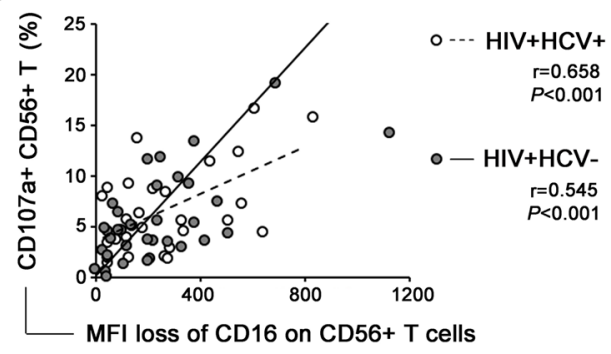

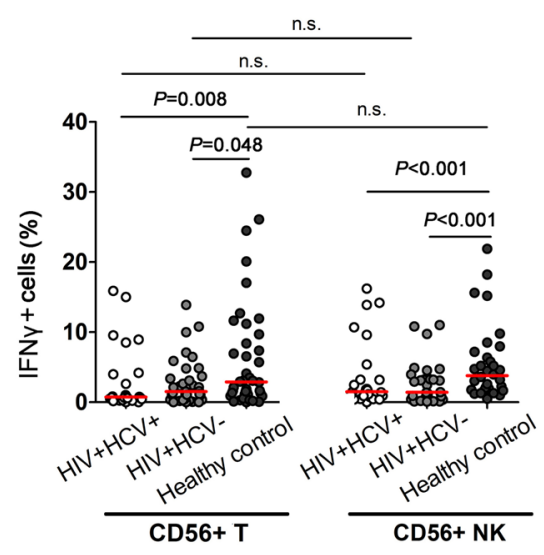

d

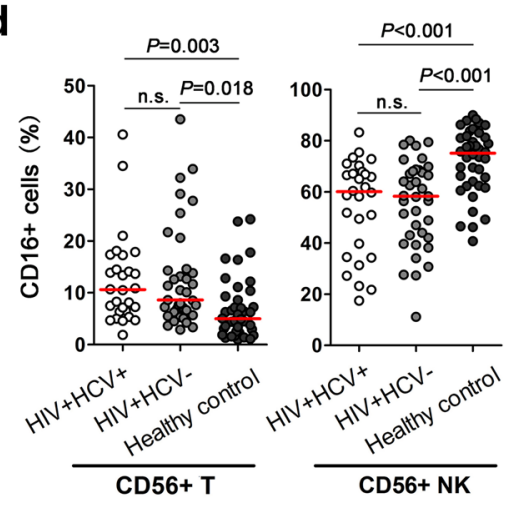

f

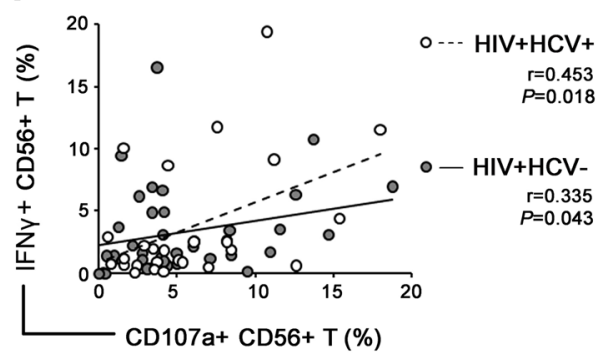




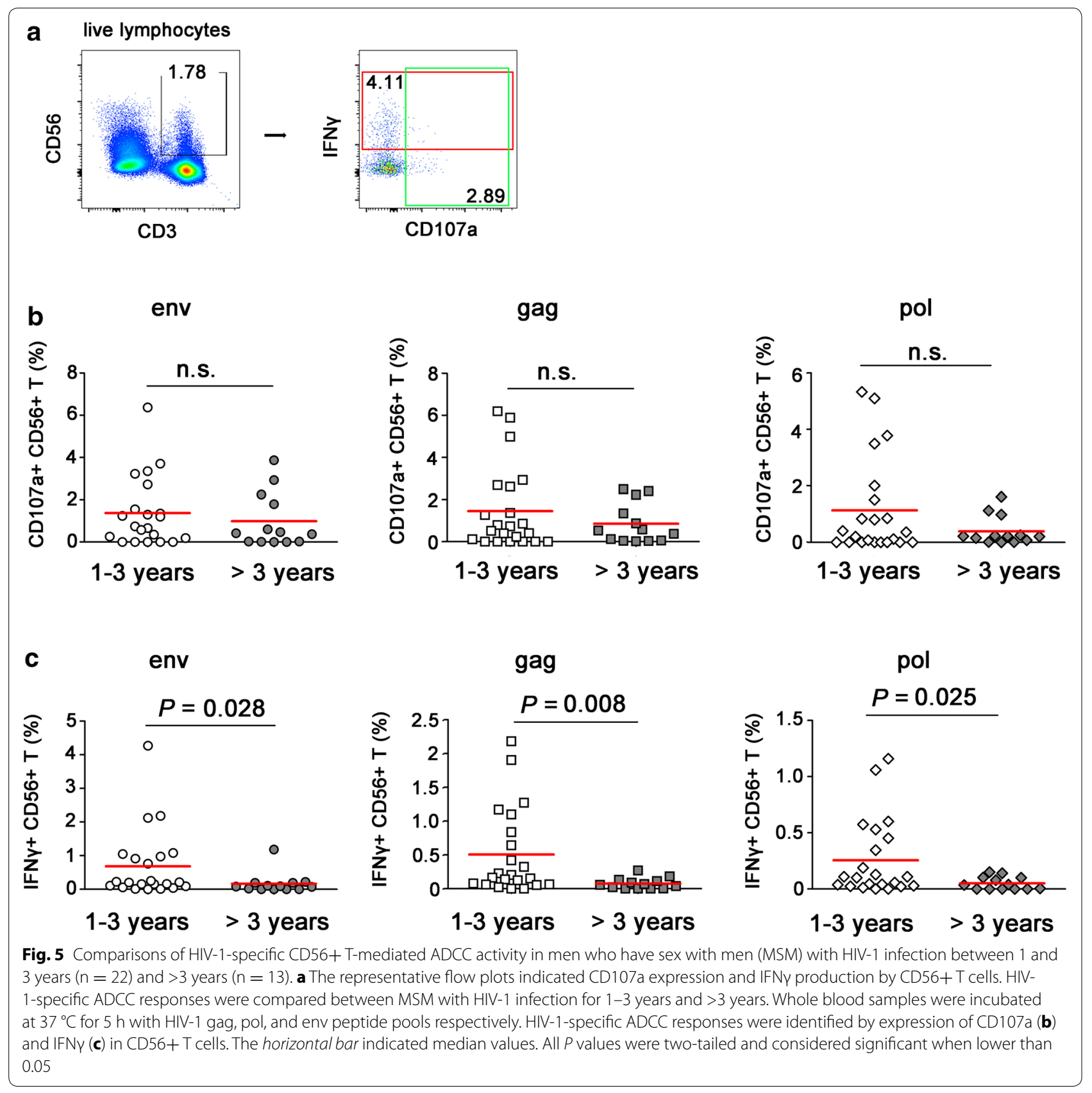

ADCC in HIV-1 infection, purified DN CD56+ T cells from 10 long-term HIV-1 infected patients were cultured with Ab-coated P815 cells in the presence or absence of broad-spectrum MMP inhibitor GM6001. The results indicated that MMP blockade increased the intensity of degranulation as measured by percentage of CD107a + cells $(P=0.004)$ and enhanced the secretion of IFNY $(P<0.001)$ (Fig. 7c, d). Therefore, MMP inhibitor treatment partially restored the impaired ADCC responses mediated by $\mathrm{CD} 56+\mathrm{T}$ cells during long-term HIV-1 infection. In addition, we found GM6001 failed to enhance antibody-dependent CD56+ $\mathrm{T}$ response in healthy donors (data not shown), indicating that MMP inhibitor increases the potentials of CD56+ T cells to mediate antibody dependent responses only in a diseasespecific manner.

\section{Discussion}

Accumulated evidence showed that antibody-dependent cellular cytotoxicity may play an important role in the control of HIV-1 infection [28-32]. However, whether CD56+ $\mathrm{T}$ cells could act as effector cells to mediate 
a
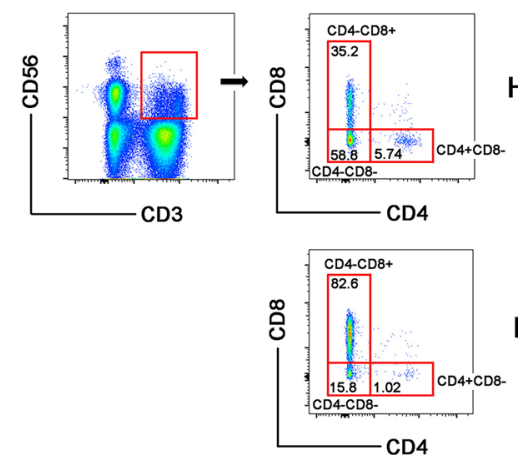

C
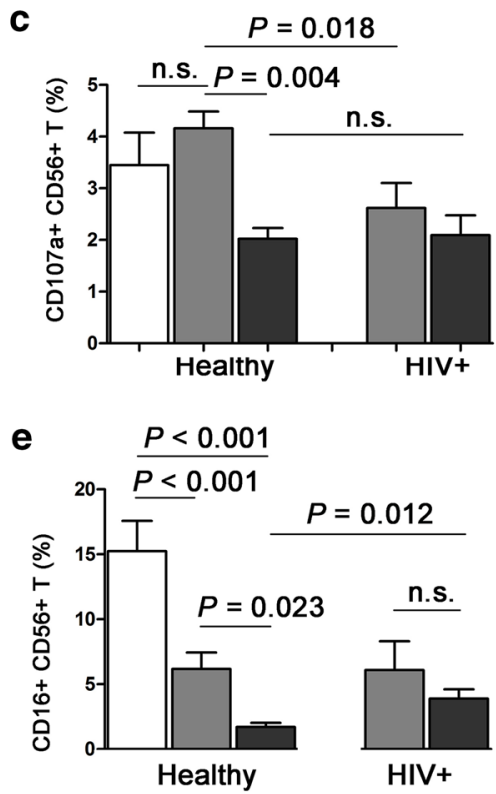

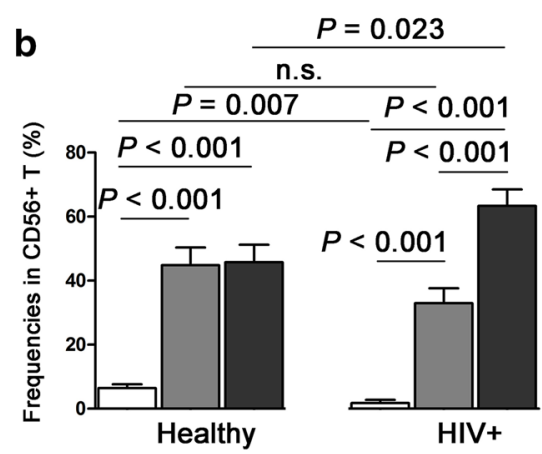

d

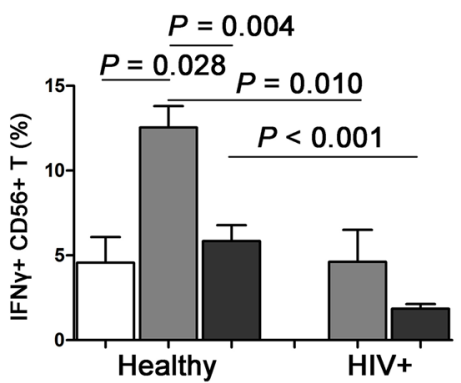

f

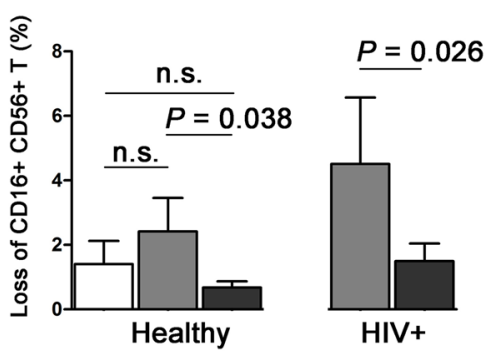

g n.s.

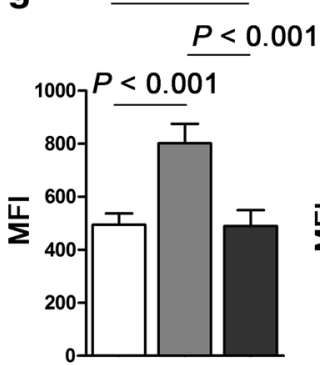

NKG2A

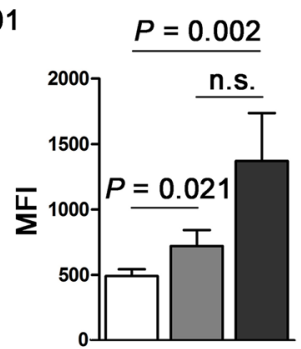

NKG2C

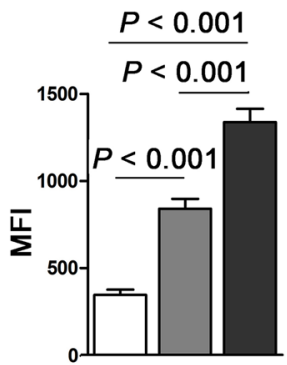

NKG2D

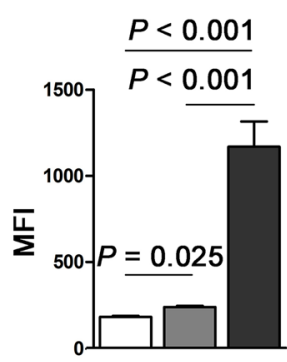

NKp44

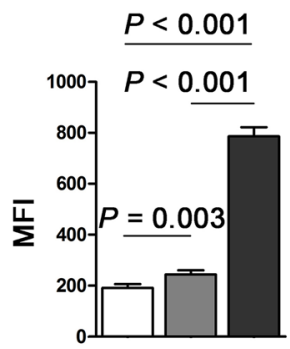

NKp46

CD4+ subset $\square$ DN subset $\square$ CD8+ subset

Fig. 6 ADCC activity mediated by CD56+T cells were mainly ascribed to CD4/CD8 double negative subset. a CD56+ T cells were divided into three subsets: CD4+ CD8-, CD4- CD8+, and CD4- CD8- (double negative, DN) subsets. Representative flow plots from a HIV-infected individual and a healthy donor were shown. $\mathbf{b}$ Frequencies of different CD56+T subsets in HIV-1+ $(n=10)$ and healthy $(n=10)$ subjects. $\mathbf{c}$, $\mathbf{d}$ ADCC activities mediated by CD56+ T subset from HIV-1+ and healthy subjects were evaluated and compared. CD107a expression (c) and IFNy production (d) of CD4+ CD8-, CD4- CD8+, and DN subset activated by Ab-bound P815 cells in HIV-1+ $(n=10)$ and healthy $(n=10)$ subjects were compared. e Comparison of CD16+ cells in individual CD56+ T subsets in HIV-1+ and healthy subjects. $\mathbf{f}$ Loss of CD16 MFI on different CD56+ T subsets in HIV-1+ and healthy subjects. $g$ Expressions of NKG2A, NKG2C, NKG2D, NKp44 and NKp46 on three CD56+ T subsets from ten healthy subjects. MFI mean fluorescence intensity. b-g Data were showing as mean \pm SD 

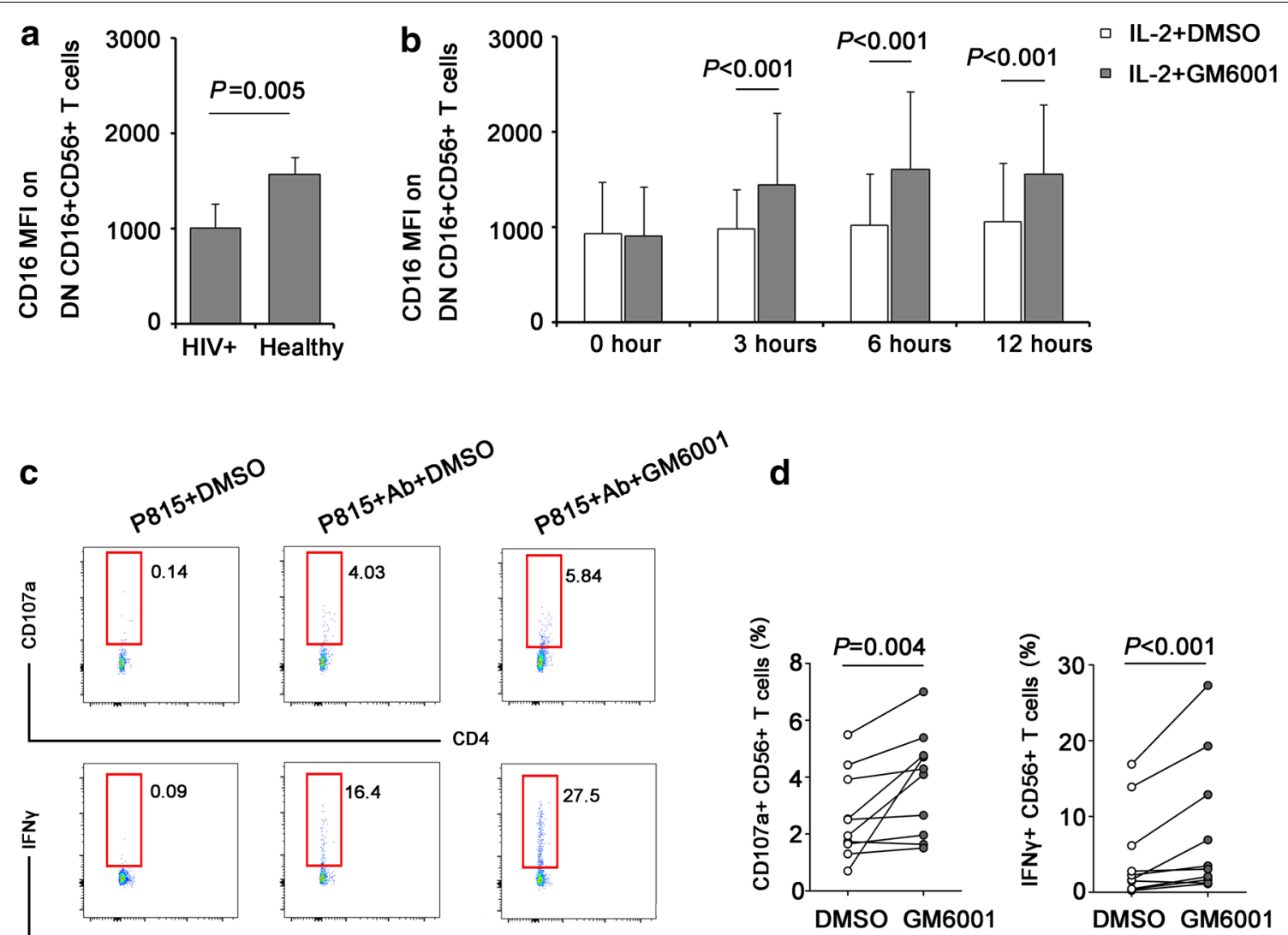

DN CD56+ T cells

Fig. 7 MMP inhibitor GM6001 partially restored the impaired ADCC capacity mediated by DN CD56+ T subset of HIV-1+ subjects. a CD16 MFI on DN CD16+ CD56+ T cells were compared between HIV+ patients $(n=10)$ and healthy controls $(n=10)$. $\mathbf{b} C D 16$ MFI on DN CD56+T cells activated by IL-2+ DMSO and IL-2+ GM6001 for 0, 3, 6, 12 h. c CD107 expression and IFNy production of DN subset from HIV+ patients ( $\mathrm{n}=10$ ) activated by P815+ DMSO, P815+ Ab+ DMSO and P815+ Ab+ GM6001 were determined by flow cytometry. $\mathbf{d}$ The percentage of CD107a+ CD56+ T cells and IFNy+ CD56+ T cells activated by Ab-bound P815 cells in the presence or absence of GM6001 from HIV-1+ subjects $(n=10)$

ADCC response is not clearly determined. CD56+ T cells were reported to produce large quantities of IFNy and played an important role in natural outcome after exposure to HIV-1 or HCV [33-35]. For example, Montoya et al. reported that the frequencies of IFN $\gamma$-producing CD56+ $\mathrm{T}$ cells activated by PMA/ionomycin were significantly higher in HIV-exposed seronegative (HESN) individuals than in chronic HIV-1-infected subjects [33]. In addition, IFN $\gamma$ production stimulated by PMA/ ionomycin was much higher in CD56+ $\mathrm{T}$ cells than in $\mathrm{NK}$ cells and common CD3+ $\mathrm{T}$ cells [33]. Kokordelis et al. demonstrated that activated CD56+ T cells could inhibit $\mathrm{HCV}$ replication in vitro in an IFN $\gamma$-dependent manner [19]. Exposure to HCV has been associated with high level of IFNY production and degranulation of CD56+ $\mathrm{T}$ cells $[35,36]$. In the present study, we showed that CD56+ $\mathrm{T}$ cells have the capacity to degranulate after cross-linking with anti-CD16 antibody and could mediate ADCC responses in vitro. The characteristics of CD56+ $\mathrm{T}$ cell-mediated ADCC responses were somewhat different from ADCC activities mediated by classic CD56+ NK cells, since NK-mediated ADCC was marked by both powerful degranulation and IFN $\gamma$ production while degranulation capacity was significantly weaker in CD56+ T cell-mediated ADCC though a comparable level of IFN $\gamma$ production was observed.

iNKT cells was identified as CD3+ V $\alpha 24-J \alpha 18(6 B 11)+$ cells and responded to CD1d-restricted lipid ligands [37]. Different from CD56+ T cells, we found iNKT expressed less CD16 than CD56+ $\mathrm{T}$ cells and failed to response to Ab-coated P815 cells, indicating that iNKT was unable to mediate ADCC responses though shared some NK characteristics. Another study has also found that iNKT cells did not mediated killing of neuroblastoma cell lines in the presence of a relevant antibody, although ADCC of mediated by NK cells was enhanced by activated iNKT 
cells [38]. CD56+ T cells were heterozygous cell population and could be subdivided into CD4+, CD8+, and DN subsets. Interestingly, unlike CD56- T cells, in which $\mathrm{CD} 4+$ or $\mathrm{CD} 8+$ single positive subset played the dominant roles in mediating immune response, DN subset within CD56+ T cells occupied a dominant frequency of total $\mathrm{CD} 56+\mathrm{T}$ cells and mediate the most robust ADCC activities. We speculated that DN subset was inclined to a NK-like function due to its negative expression of CD4 and CD8 and was unable to activate in a MHCdependent manner. In addition, nature killer cell receptor (NKR) patterns were quite different among CD4+, $\mathrm{CD} 8+$, and DN subsets. CD4+ subset is characterized by the weakest expressions of NK cell-distinctive markers (NKG2A, NKG2C, NKG2D, NKp44 and Nkp46), which are expressed highest on CD8+ cells subset (except NKG2A), and then DN cells. The moderate frequencies of both CD16 and NK cell-specific markers may contribute to the highest ADCC activity mediated by DN subset.

In this study, we found the capacity of CD56+ $\mathrm{T}$ cells to mediate nonspecific ADCC function in long-term HIVinfected FPDs was significantly weaker than in healthy controls. The decreased CD56+ T cell-mediated ADCC activities in HIV-1 infection might be ascribed to the functional impairment since the frequencies of CD56+ $\mathrm{T}$ cells were comparable among groups (Fig. $4 \mathrm{c}$ ). In addition, frequencies of CD16+ CD56+ T cells were found higher in HIV-1 infected subjects, which was different from the reduced frequency of CD16+ NK cells in HIV$1+$ patients as reported previously and observed in this study $[27,39]$. Considering that frequencies of CD16+ CD56+ T cells in DN subset was similar between HIV-1 infected subjects and healthy control, increased frequencies of CD16+ CD56+ subset in CD8+ CD56+ T cells was the main source of elevated CD16 on bulk CD56+ $\mathrm{T}$ cells in HIV-1+ subjects. Due to the loss of CD4+ T cells in HIV-1 infection, we also found a decreased frequency of CD4+ CD56+ $\mathrm{T}$ cells in HIV-1 infection. As a result, the frequency of CD8 + CD56+ $T$ cells was increased. However, CD8+ CD56+ T subset showed less capacity to mediate ADCC compared with DN subset. Combined the characteristics of less frequency, higher CD16 expression, moderated activate NKR expression, and highest ADCC activity of DN subset, we speculated that a balance between expression of surface CD16 and NKR might determine the ADCC capacities of different CD56+ T subsets.

Theoretically, nonspecific ADCC activities detected by Ab-opsonized P815 cells merely evaluated the potentials of effector cells to mediate degranulation and cytokine secretion, while failed to consider other important participants involved in ADCC response, such as $\mathrm{Ab}$ factor. In this study, we employed a HIV-1-specific CD56+ T cell-mediated ADCC assay using whole blood samples incubating with HIV-1 peptide pools to identify HIV1-specific ADCC activities in HIV-1-infected individuals. Our data indicated that HIV-1-specific ADCC activity was also declined in MSM with HIV-1 infection longer than 3 years. To rule out TCR-dependent CD56+ T responses, whole blood samples used in HIV-1-specific ADCC assay were replaced by PBMCs samples. The results indicated that TCR-dependent CD56+ $\mathrm{T}$ cell responses (indicated by intracellular IFNY production) were significantly lower than TCR-dependent CD56- T cell responses (Additional file 3: Fig. S3). The mean values of IFN $\gamma$ producing CD56+ T cells stimulated by env, gag and env were all less than $0.2 \%$, which were much lower than HIV antibody-dependent CD56+ T responses and could be ignored in the CD56+ T-mediated HIV-1-specific ADCC study. Moreover, the impaired ADCC activities mediated by CD56 $+\mathrm{T}$ cells may not only ascribe to the changes of phenotype, functionality and subset distribution of CD56+ T cells per se, but also associate with the alteration of titer, subclassand clonal natureof antibody involved in ADCC responses [5, 40-43].

\section{Conclusions}

In summary, our finding indicated that CD56+ $\mathrm{T}$ cells from long-term HIV-1-infected patients displayed weaker antibody-dependent capabilities of cytotoxicity and IFNY production. The impaired ADCC activities mediated by CD56+ $\mathrm{T}$ cells might represent a novel mechanism of dysregulated immune response in chronic HIV-1-infected patients, which shed light on the development of new target for HIV vaccine design or immune therapy.

\section{Methods}

\section{Study population}

A total of 111 HIV-1-infected participants and 36 healthy controls were recruited in this study. Fasted venous blood samples were collected from each participant. Routine blood tests, clinical biomedical tests, and CD4 +/CD8+ $\mathrm{T}$ cell counts were performed by local CDC. Peripheral blood mononuclear cells (PBMCs) were prepared from fresh EDTA anti-coagulated peripheral blood using Histopaque-1077 (Sigma, 10,771-500 $\mathrm{ml}$ ) as described elsewhere [21] and were stored $\left(5 \times 10^{6}\right.$ cells per vial) in liquid nitrogen till use. Serum and EDTA anti-coagulated plasma were stored at $-80^{\circ} \mathrm{C}$ until use.

HIV-1 infection was screened by an ELISA assay (GBI Biotech, Beijing, China) for HIV antibody, and positive tests were confirmed by HIV Blot 2.2 WB assay (Genelabs Diagnostics, Singapore). The status of anti-HCV antibodies was determined using the ARCHITECT Anti-HCV System (Abbott Diagnostics, Abbott Park, 
USA). Plasma level of HIV-1 RNA was measured with the Standard Amplicor HIV Monitor assay, version 2.0 (Roche Diagnostics, Indianapolis, IN, USA), according to the manufacturer's protocols. The lower limit of detection was 40 copies/ml. Plasma HCV RNA level was quantified with 2nd Cobas Ampliprep/CobasTaqman (CAP/ CTM) HCV test system (Roche, Branchburg, NJ, USA) with a detection limit of $15 \mathrm{IU} / \mathrm{ml}$.

\section{FPDs and healthy controls}

The study involved 76 anti-HIV-positive former plasma donors (FPDs) (Table 1), recruited from a village in central China in July 2012. Among the 76 HIV-1+ individuals, 36 were coinfected with $\mathrm{HCV}$ and 40 were infected by HIV-1 alone. The infection time of these HIV-1+ patients was highly uniform (13-16 years), and all individuals were infected by a single closely related HIV-1 strain via unregulated commercial plasma donation practices in the late 1990s. HCV infection was characterized by positive anti-HCV response and positive results for $\mathrm{HCV}$-RNA detection. All recruited subjects were negative for hepatitis B surface antigen (HBsAg) and had never received any forms of HCV-specific antiviral therapy. All HIV-1-positive FPDs had received regular or intermittent first-line antiretroviral therapy. 36 healthy adults from the same village who were negative for $\mathrm{HBV} / \mathrm{HCV} / \mathrm{HIV}-1$ infection were recruited as controls (Table 1 ).
MSM

35 HIV-1 positive men who have sex with men (MSM) were recruited from Beijing city. Subjects were divided into two groups according to the length of HIV-1 infection: $1-3$ years $(n=22)$ and $>3$ years $(n=13)$ (Table 2$)$. All MSM subjects were naïve of antiretroviral therapy.

\section{CD16/CD32 surface staining}

To compare the surface expression of CD16 and CD32 on circulating CD56+ T cells, CD56+ NK cells and CD56$\mathrm{T}$ cells, PBMCs from 10 healthy controls were stained with anti-CD3 Pacific Blue (clone UCHT1), anti-CD56 PE-Cy7 (clone B159), anti-CD16 APC-Cy7 (clone 3G8),

Table 2 Characteristics of HIV-1-infected MSM recruited in the study

\begin{tabular}{|c|c|c|}
\hline \multirow[t]{2}{*}{ Characteristics } & \multicolumn{2}{|c|}{ Duration of HIV-1 infection } \\
\hline & $1-3$ years & $>3$ years \\
\hline Number & 22 & 13 \\
\hline Age (years) ${ }^{\dagger}$ & $30.2(6.6)$ & $34.5(7.0)$ \\
\hline Deduced infection time (years) ${ }^{\dagger}$ & $2.0(0.6)$ & $5.6(2.1)$ \\
\hline HIV RNA (copies/ml) ${ }^{\dagger}$ & $25,611(30,255)$ & $27,657(30,144)$ \\
\hline CD4 cells $/\left.\mu\right|^{\dagger}$ & $356(105)$ & $348(241)$ \\
\hline CD8 cells $/\left.\mu\right|^{+}$ & $924(312)$ & $874(247)$ \\
\hline
\end{tabular}

${ }^{\dagger}$ Mean \pm standard deviation (SD)

Table 1 Characteristics of HIV-1-infected former plasma donors (FPDs) and control individuals

\begin{tabular}{|c|c|c|c|}
\hline Characteristics & HIV-1-monoinfected & HIV-1/HCV-coinfected & Healthy \\
\hline Number & 40 & 36 & 36 \\
\hline Female* & $25(62.5)$ & $20(55.6)$ & $18(50.0)$ \\
\hline Age $(\text { years) })^{\dagger}$ & $43(9.4)$ & $44(9.3)$ & $46(10.2)$ \\
\hline Deduced infection time (years) ${ }^{\dagger}$ & $15.1(1.5)$ & $14.8(1.5)$ & $N A^{a}$ \\
\hline \multicolumn{4}{|l|}{ Clinical data } \\
\hline $\mathrm{ALT}(\mathrm{IU} / \mathrm{L})^{\mathrm{tb}}$ & $22.5(25.1)$ & $33.0(50.5)$ & 19 (12.0) \\
\hline $\operatorname{AST}(I U / L)^{\dagger c}$ & $29.0(24.9)$ & $35.5(57.5)$ & $22(11.6)$ \\
\hline \multicolumn{4}{|l|}{ HIV-status } \\
\hline Anti-HIV & Positive & Positive & NA \\
\hline HIV RNA (copies/ml) ${ }^{\dagger}$ & $11,452(8933)$ & $11,075(7866)$ & NA \\
\hline CD4 cells/ $\left.\mu\right|^{\dagger}$ & $384(234)$ & $403(233)$ & NA \\
\hline CD8 cells $/\left.\mu\right|^{\dagger}$ & $936(394)$ & $850(517)$ & NA \\
\hline \multicolumn{4}{|l|}{ HCV-status } \\
\hline Anti-HCV & Negative & Positive & NA \\
\hline HCV RNA $\left(\log _{10} \mid \mathrm{U} / \mathrm{ml}\right)^{\dagger}$ & $0(0)$ & $6.4(0.9)$ & NA \\
\hline \multicolumn{4}{|l|}{ HCV genotype } \\
\hline $1 b^{*}$ & NA & $15(41.7)$ & NA \\
\hline $2 a^{*}$ & NA & $20(55.6)$ & NA \\
\hline Others* & NA & $1(2.7)$ & NA \\
\hline
\end{tabular}

* Number of cases (number/total in \%)

+ Mean \pm standard deviation (SD)

a Not applicable, ${ }^{b}$ alanine aminotransferase, ${ }^{c}$ aspartate aminotransferase 
and anti-CD32 PerCP-eFluor 710 (clone 6C4). All antibodies were purchased from BD Biosciences (San Diego, CA, USA) except CD32 from eBiosciences (San Diego, CA, USA). Samples were analyzed on BD FACS Fortessa (BD Biosciences, San Jose, CA, USA) and the frequencies of CD16+ or CD32+ cells in CD56+ T cells, CD56+ NK cells and CD56- T cells were calculated and compared.

\section{Image analysis of CD16/CD32 expression}

To identify the expression of CD16 and CD32 on CD56+ $\mathrm{T}$ cells, CD56+ NK cells and CD56- T cells at single-cell level, $1 \times 10^{5}$ PBMC from three healthy controls were stained with anti-CD3 Pacific Blue (clone UCHT1), antiCD56 PE-Cy7 (clone B159), anti-CD16 APC-Cy7 (clone 3G8) and anti-CD32 PerCP-eFluor 710 (clone 6C4) and were run on an ImageStream ${ }^{X}$ MarkII system (Amnis Corporation, Seattle, WA, USA). 20,000 events were collected for each sample and single color control was used to create a compensation matrix to correct for spectral overlap. Collected data were analyzed using IDEAS 3.0 software (Amnis Corporation, Seattle, WA, USA).

\section{CD56+ $T$ cells sorting}

PBMCs were stained with anti-CD3 Pacific Blue (clone UCHT1, BD Biosciences), anti-CD56 PE-Cy7 (clone B159, BD Biosciences) for $30 \mathrm{~min}$ at room temperature. CD56+ $\mathrm{T}$ cells, CD56+ NK cells and CD56- T cells were sorted by BD FACS ArialII (BD Biosciences, San Jose, CA) and only cells with purity $>95 \%$ were used in subsequent experiments.

\section{Activation of purified CD56+ T cells by CD16/CD32 cross-linking}

$1 \times 10^{5}$ purified CD56+ $\mathrm{T}$ cells from healthy controls were stimulated with $10 \mu \mathrm{g} / \mathrm{ml}$ of purified anti-CD16 antibody (clone 3G8, Santz Cruz biotechnology, Santa Cruz, CA, USA) or $10 \mu \mathrm{g} / \mathrm{ml}$ purified anti-CD32 antibody (clone 3D3, Santz Cruz biotechnology) or mouse IgG1(к) (clone X40, BD Biosciences) isotype control for $30 \mathrm{~min}$ on ice. Cells were washed to remove unbound antibody and incubated with $10 \mu \mathrm{g} / \mathrm{ml}$ of goat anti-mouse IgG1 $\mathrm{F}\left(\mathrm{ab}^{\prime}\right)_{2}$ for $5 \mathrm{~h}$ (Santz Cruz biotechnology, Santa Cruz, USA) at $37^{\circ} \mathrm{C}$. Cells were washed and stained with antiCD3 Pacific Blue (clone UCHT1), anti-CD56 PE-Cy7 (clone B159) and anti-CD107a PE-Cy5 (clone H4A3) and fixed by $2 \%$ paraformaldehyde (PFA). All data were acquired on BD FACS Fortessa (BD Biosciences, San Jose, CA, USA) and analyzed by FlowJo software (Treestar, Ashland, OR, USA).

Evaluation of CD56+ T-mediated nonspecific ADCC activity The nonspecific ADCC assay was performed as previously described, in which the mouse mastocytoma cell line P815 was used as target cells [27]. Briefly, PBMC were stimulated with P815 cells alone or P815 cells/ P815-specific Abs (P815/Abs) complex (1:100 dilution of polyclonal rabbit anti-mouse lymphocyte serum, Accurate Chemical \& Scientific Corp., Westbury, NY) at an E:T ratio of 10:1. Brefeldin-A $(10 \mu \mathrm{g} / \mathrm{ml}$, Sigma, St Louis, MO, USA), GolgiStop (5 $\mu \mathrm{g} / \mathrm{ml}$, BD Biosciences) and anti-CD107a PE-Cy5 (clone H4A3, BD Biosciences) were added immediately to cell medium and incubated for $6 \mathrm{~h}$. Cells were fixed by $2 \%$ PFA and stained with antiCD3 Pacific Blue (clone UCHT1), anti-CD56 PE-Cy7 (clone B159), anti-CD16 APC-Cy7 (clone 3G8), antiCD4 PE (clone RPA-T4), anti-CD8 APC (clone RPA-T8), and anti-IFNY FITC (clone 25,723.11). To evaluate the response time of antibody-dependent response mediated by CD $56+\mathrm{T}$ and NK cells, PBMC were cocultured with P815/Abs for 2, 4 and $6 \mathrm{~h}$ and fixed and stained as above. All data were acquired on BD FACS Fortessa (BD Biosciences, San Jose, CA, USA) and analyzed by FlowJo software (Treestar, Ashland, OR, USA).

\section{Rapid fluorometric assay to test cytotoxicity mediated by CD56+ $T$ cells}

Based on methods adapted from a rapid fluorometric ADCC (RFADCC) assay [44], $1 \times 10^{6}$ target cells (P815) were double-stained with $5 \mu \mathrm{M}$ PKH-26 (Sigma, St. Louis, MO, USA) and $5 \mu \mathrm{M}$ 5-(and-6)-carboxyfluorescein diacetate succinimidyl ester (CFSE) (Molecular Probes, Eugene, OR, USA). Purified CD56+ T cells, NK cells and $\mathrm{T}$ cells were used as effector cells and incubated with P815/Abs complex or P815 alone in a microtiter plate with an E:T ratio of 1:1. After $10 \mathrm{~h}$ incubation, cells were washed and fixed in cold $2 \%$ paraformaldehyde. Samples were run on BD FACS Fortessa (BD Biosciences, San Jose, CA, USA) and data were analyzed by FlowJo software (Treestar, Ashland, OR, USA).

\section{HIV-1 specific peptides}

HIV-1 gag, pol, env solid-phase peptide pools containing 20-mers (overlapping by 10 amino acids) from HIV-1 strain CN54 were synthesized to 95\% purity by Bio-Scientific Co., Shanghai, China. Peptides were dissolved to a concentration of $1 \mathrm{mg} / \mathrm{ml}$ in RPMI 1640 containing $10 \%$ dimethyl sulphoxide (DMSO) as stock solutions, and working solutions were obtained by further dilution to a final concentration of $1 \mu \mathrm{g} / \mathrm{ml}$.

\section{CD56+ T-mediated HIV-1-specific ADCC assay}

Whole blood samples were incubated with HIV-1 gag, pol and env peptide pools respectively at $37{ }^{\circ} \mathrm{C}$ for $5 \mathrm{~h}$. Brefeldin-A (10 $\mu \mathrm{g} / \mathrm{ml}$, Sigma), GolgiStop $(5 \mu \mathrm{g} / \mathrm{ml}$, BD Biosciences) and anti-CD107a APC (clone H4A3, $20 \mu \mathrm{l} /$ $\mathrm{ml}, \mathrm{BD}$ Biosciences) were added immediately to the cell 
medium and incubated for $6 \mathrm{~h}$. Samples incubated with phorbol-12-myristate-13-acetate (PMA) $(1 \mathrm{mg} / \mathrm{ml})$ plus ionomycin $(1 \mathrm{mg} / \mathrm{ml})$ were used as positive controls and samples incubated with DMSO $(1 \mathrm{mg} / \mathrm{ml}$, Sigma) were used as negative controls. Samples were surface-stained with live/dead dye Amcyan (Invitrogen, Carlsbad, CA, USA), anti-CD3-PerCP (clone SK7) and anti-CD56-PE (clone B159), and then lysed, permeabilized and intracellularly stained with anti-IFNy Alexa Fluor700 (clone B27, BD Biosciences) and anti-CD107a APC (clone H4A3). All data were acquired on BD FACS Fortessa (BD Biosciences, San Jose, CA, USA) and analyzed by FlowJo software (Treestar, Ashland, OR, USA).

\section{ELISA assay}

$1 \times 10^{5}$ sorted CD56+ $\mathrm{T}$ cells were co-cultured with $1 \times 10^{5}$ P815 cells alone, $1 \times 10^{5}$ P815 cells plus P815-specific Abs, or medium alone for $24 \mathrm{~h}$ at $37^{\circ} \mathrm{C}$. The level of secreted IFNY in culture supernatants was detected by ELISA (cat\# 88-7316, eBioscience, San Diego, CA, USA) according to the manufacturer's instruction. The sensitivity of the ELISA kit was $4 \mathrm{pg} / \mathrm{ml}$.

\section{Identification of peripheral iNKT cells}

Human peripheral invariant NKT (iNKT) cells were characterized as CD3+ $\mathrm{T}$ cells expressing a specific TCR (V $\alpha 24-J \alpha 18-V \beta 11)$. To identify iNKT cells, PBMCs were surface-stained with anti-CD3 Pacific Blue (clone UCHT1, BD Biosciences) and antiV $\alpha 24-J \alpha 18$ FITC (clone 6B11, BD Biosciences). CD3+ V $\alpha 24-\mathrm{J} \alpha 18+$ double positive cells were defined as iNKT cells. To detect CD16, CD161 and CD69 expression on iNKT and CD56+ T cells, PBMC were surface-

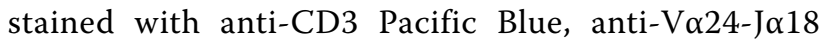
FITC (clone 6B11), anti-CD56 PE-Cy7 (clone B159), anti-CD16 (clone eBioCB16, eBioscience), anti-CD161 (clone DX12, BD Biosciences) and anti-CD69 (clone FN50, BD Biosciences). Samples were analyzed on BD FACS Fortessa (BD Biosciences, San Jose, CA, USA) and the frequencies of $\mathrm{CD} 16+$ or $\mathrm{CD} 32+$ cells in CD56+ T cells, CD56+ NK cells and CD56- T cells were calculated and compared.

\section{Recovery of impaired antibody-dependent CD56+ $\mathrm{T}$ cell responses in HIV+ subjects by MMP inhibitor}

$1 \times 10^{5}$ purified DN CD56 $+\mathrm{T}$ cells were cultured in interleukin-2-supplemented medium in the presence or absence of broad-spectrum MMP inhibitor GM6001 ( $5 \mathrm{mM}$ ) or DMSO for $0,3,6$ and $12 \mathrm{~h}$. CD16 expression (MFI) was detected by flow cytometry at each point. Additionally, changes in P815/Ab-stimulated purified CD56+ $\mathrm{T}$ cell responses (at an E:T ratio of 1:1) following
GM $6001(50 \mu \mathrm{M})($ Sigma) treatment was analyzed after $6 \mathrm{~h}$ of coculture. An equivalent volume of DMSO (Sigma) was used as control. Cells were washed/stained as described above and fixed in cold 2\% PFA. All data were acquired on BD FACS Fortessa (BD Biosciences, San Jose, CA, USA) and analyzed by FlowJo software (Treestar, Ashland, OR, USA).

To determine whether GM6001 could restore the capacity of dysfunctional CD56+ $\mathrm{T}$ cell-medicated ADCC in HIV-1 infected subjects, purified DN (CD4CD8-) CD56+ $\mathrm{T}$ cells were cultured in interleukin-2 (IL2)-supplemented medium in the presence of $5 \mu \mathrm{M}$ GM6001(Santz Cruz biotechnology, Santa Cruz, CA, USA) or an equivalent amount of DMSO vehicle alone. The degranulating capacities of CD56+ T cells following stimulation with P815 cells or Ab-coated P815 cells were analyzed and compared. After stained with antiCD107a PE-Cy5 (clone H4A3, BD Biosciences) and antiIFNY FITC (clone 25,723.11, BD Biosciences), cells were washed by PBS and fixed by $2 \%$ paraformaldehyde (PFA). All data were acquired on BD FACS Fortessa and analyzed by FlowJo software.

\section{Statistical analysis}

All the statistical and graphic analyses were performed using GraphPad Prism 5.0 (GraphPad Software, La Jolla, CA, USA) or Microsoft Excel 2007. Comparisons between groups were performed using Mann-Whitney $U$ test, nonparametric $t$ test, or Wilcoxon matched-pairs signed rank test when necessary. The Spearman's correlation test was used to evaluate correlations between groups. All $P$ values were two-tailed and considered significant when lower than 0.05 .

\section{Additional files}

Additional file 1: Figure S1. Purity detection of sorted CD56+ T cells. CD56+T cells were sorted by BD FACSAriall and detected for purity with BD FACS Fortessa. The figure showed a representative result for purity test (96.4\%).

Additional file 2: Figure S2. Comparison of the response time of non-specific ADCC mediated by CD56+T and CD56+ NK cells. a Levels of CD107a expression and IFNy production were detected from CD56+ T cells and CD56+ NK cells incubated with P815 plus Abs for 2, 4,6 h by flow cytometry. $\mathbf{b}$ Comparison of the frequencies of CD107a+ cells and IFNY + cells between CD56+ T cells and CD56+ NK cells in different responding time $(n=10)$.

Additional file 3: Figure S3. Comparison of the TCR-dependent responses mediated by $C D 56+T$ and $C D 56-T$ cells. a PBMC cells from HIV-1-infected patients were activated by env, gag and pol peptides for $6 \mathrm{~h}$. SEB activation and medium alone were set as positive and negative controls respectively. Intracellular IFNy production was detected from activated CD56+ T cells and CD56- T cells by flow cytometry. b Comparison of the frequencies of IFN + cells between activated CD56+T cells and CD56-T cells from HIV-1-infected patients $(n=10)$. 


\begin{abstract}
Abbreviations
ADCC: antibody-dependent cellular cytotoxicity; NK: natural killer; HIV-1: human immunodeficiency virus type-1; HCV: hepatitis C virus; MMP: matrix metalloprotease; AIDS: acquired immune deficiency syndrome; iNKT: invariant NKT; TCR: T cell receptor; a-GC: a-galactosylceramide; MHC: major histocompatibility complex; PBMC: peripheral blood mononuclear cell; IFNy: interferon-ү; FPDs: former plasma donors; MSM: men who have sex with men; DN: double negative subset; HESN: HIV-exposed seronegative; 6B11+: Va24-Ja18+; NKR: nature killer cell receptor; CAP/CTM: Cobas Ampliprep/ CobasTaqman; HBsAg: hepatitis B surface antigen; PFA: paraformaldehyde; DMSO: dimethyl sulphoxide; PMA: phorbol-12-myristate-13-acetate.
\end{abstract}

\section{Authors' contributions}

$X F, L Z, Z X, X H$ and SW performed the experiments and contributed to data acquisition. XF and $L Z$ analyzed the data. TS and $\mathrm{HL}$ conceived and designed the study and experiments. XF, LZ and TS wrote and HL edited the paper. All authors read and approved the final manuscript.

\section{Author details}

${ }^{1}$ Department of Microbiology and Center of Infectious Diseases, Peking University Health Science Center, 38 Xueyuan Road, Haidian District, Beijing 100191, China. ${ }^{2}$ State Key Laboratory of Infectious Disease Prevention and Control, National Center for AIDS/STD Control and Prevention, Collaborative Innovation Center for Diagnosis and Treatment of Infectious Diseases, China CDC, Beijing, China.

\section{Acknowledgements}

We thank all participants recruited in this study and appreciate staff in Shangcai CDC and Beijing CDC for helping to collect blood samples.

\section{Competing interests}

The authors declare that they have no competing interests.

\section{Ethics approval and consent to participate}

The study is conducted in accordance with the ethical principles set out in the declaration of Helsinki, and written consent was obtained prior to data collection. The study was approved by the institutional review authorities of Peking University Health Science Center (Approval ID: PKUPHLL20090011).

\section{Funding}

This work was financially supported by grants from the National Natural Science Foundation of China (81271826), the National Science and Technology Major Project for Infectious Diseases (2014ZX10001001-002-004), and State

Key Laboratory of Infectious Disease Prevention and Control (2015SKLID506).

Received: 29 July 2016 Accepted: 30 October 2016

Published online: 04 November 2016

\section{References}

1. Sanderson CJ, Clark IA, Taylor GA. Different effector cell types in antibodydependent cell-mediated cytotoxicity. Nature. 1975;253:376-7.

2. Lanier LL, Ruitenberg JJ, Phillips JH. Functional and biochemical analysis of CD16 antigen on natural killer cells and granulocytes. J Immunol. 1988;141:3478-85.

3. Morel PA, Ernst LK, Metes D. Functional CD32 molecules on human NK cells. Leuk Lymphoma. 1999;35:47-56.

4. Baum LL, Cassutt KJ, Knigge K, Khattri R, Margolick J, Rinaldo C, Kleeberger CA, Nishanian P, Henrard DR, Phair J. HIV-1 gp120-specific antibody-dependent cell-mediated cytotoxicity correlates with rate of disease progression. J Immunol. 1996;157:2168-73.

5. Lambotte O, Ferrari G, Moog C, Yates NL, Liao HX, Parks RJ, Hicks CB, Owzar K, Tomaras GD, Montefiori DC, et al. Heterogeneous neutralizing antibody and antibody-dependent cell cytotoxicity responses in HIV-1 elite controllers. AIDS. 2009;23:897-906.

6. Gomez-Roman VR, Patterson LJ, Venzon D, Liewehr D, Aldrich K, Florese R, Robert-Guroff M. Vaccine-elicited antibodies mediate antibody-dependent cellular cytotoxicity correlated with significantly reduced acute viremia in Rhesus macaques challenged with SIVmac251. J Immunol. 2005; 174:2185-9.

7. Rerks-Ngarm S, Pitisuttithum P, Nitayaphan S, Kaewkungwal J, Chiu J, Paris R, Premsri N, Namwat C, de Souza M, Adams E, et al. Vaccination with ALVAC and AIDSVAX to prevent HIV-1 infection in Thailand. N Engl J Med. 2009;361:2209-20.

8. Cohen J. AIDS research. Novel antibody response may explain HIV vaccine success. Science. 2011;333:1560.

9. Haynes BF, Gilbert PB, McElrath MJ, Zolla-Pazner S, Tomaras GD, Alam SM, Evans DT, Montefiori DC, Karnasuta C, Sutthent R, et al. Immunecorrelates analysis of an HIV-1 vaccine efficacy trial. N Engl J Med. 2012;366:1275-86.

10. Madhavi V, Navis M, Chung AW, Isitman G, Wren LH, De Rose R, Kent SJ, Stratov I. Activation of NK cells by HIV-specific ADCC antibodies: role for granulocytes in expressing HIV-1 peptide epitopes. Hum Vaccin Immunother. 2013;9:1011-8.

11. Kramski M, Schorcht A, Johnston AP, Lichtfuss GF, Jegaskanda S, De Rose R, Stratov I, Kelleher AD, French MA, Center RJ, et al. Role of monocytes in mediating HIV-specific antibody-dependent cellular cytotoxicity. J Immunol Methods. 2012;384:51-61.

12. Smalls-Mantey A, Connors M, Sattentau QJ. Comparative efficiency of HIV-1-infected T cell killing by NK cells, monocytes and neutrophils. PLoS ONE. 2013;8:e74858.

13. Joshi T, Ganesan LP, Cheney C, Ostrowski MC, Muthusamy N, Byrd JC, Tridandapani S. The Ptdlns 3-kinase/Akt pathway regulates macrophagemediated ADCC against B cell lymphoma. PLoS ONE. 2009;4:e4208.

14. Duerst R, Werberig K. Cells of the $\mathbf{J 7 7 4}$ macrophage cell line are primed for antibody-dependent cell-mediated cytotoxicity following exposure to gamma-irradiation. Cell Immunol. 1991;136:361-72.

15. Lu PH, Negrin RS. A novel population of expanded human CD3+ CD56+ cells derived from T cells with potent in vivo antitumor activity in mice with severe combined immunodeficiency. J Immunol. 1994;153:1687-96.

16. Godfrey DI, MacDonald HR, Kronenberg M, Smyth MJ, Van Kaer L. NKT cells: what's in a name? Nat Rev Immunol. 2004;4:231-7.

17. Godfrey DI, Hammond KJ, Poulton LD, Smyth MJ, Baxter AG. NKT cells: facts, functions and fallacies. Immunol Today. 2000;21:573-83.

18. Ye L, Wang X, Wang S, Wang Y, Song L, Hou W, Zhou L, Li H, Ho W. CD56+ T cells inhibit hepatitis $C$ virus replication in human hepatocytes. Hepatology. 2009;49:753-62.

19. Kokordelis $\mathrm{P}$, Kramer B, Boesecke C, Voigt E, Ingiliz P, Glassner A, Wolter F, Srassburg CP, Spengler U, Rockstroh JK, Nattermann J. CD3(+)CD56(+) natural killer-like T cells display anti-HCV activity but are functionally impaired in HIV(+) patients with acute hepatitis C. J Acquir Immune Defic Syndr. 2015;70:338-46.

20. Smyth MJ, Cretney E, Kelly JM, Westwood JA, Street SE, Yagita H, Takeda K, van Dommelen SL, Degli-Esposti MA, Hayakawa Y. Activation of NK cell cytotoxicity. Mol Immunol. 2005;42:501-10.

21. He X, Li D, Luo Z, Liang H, Peng H, Zhao Y, Wang N, Liu D, Qin C, Wei $\mathrm{Q}$, et al. Compromised NK cell-mediated antibody-dependent cellular cytotoxicity in chronic SIV/SHIV infection. PLoS ONE. 2013;8:e56309.

22. Poggi A, Tomasello E, Costa P. NKRP1A and p40 molecules are involved in regulation of activation and maturation of human NK cells. Res Immunol. 1997;148:179-84.

23. Radulovic K, Rossini V, Manta C, Holzmann K, Kestler HA, Niess JH. The early activation marker CD69 regulates the expression of chemokines and CD4 T cell accumulation in intestine. PLoS ONE. 2013;8:e65413.

24. Parsons MS, Tang CC, Jegaskanda S, Center RJ, Brooks AG, Stratov I, Kent SJ. Anti-HIV antibody-dependent activation of NK cells impairs NKp46 expression. J Immunol. 2014;192:308-15.

25. Tang CC, Isitman G, Bruneau J, Tremblay C, Bernard NF, Kent SJ, Parsons MS. Phenotypical and functional profiles of natural killer cells exhibiting matrix metalloproteinase-mediated CD16 cleavage after anti-HIV antibody-dependent activation. Clin Exp Immunol. 2015;181:275-85.

26. Grzywacz B, Kataria N, Verneris MR. CD56(dim)CD16(+) NK cells downregulate CD16 following target cell induced activation of matrix metalloproteinases. Leukemia. 2007;21:356-9 (author reply 359)

27. Liu Q, Sun Y, Rihn S, Nolting A, Tsoukas PN, Jost S, Cohen K, Walker B, Alter G. Matrix metalloprotease inhibitors restore impaired NK cell-mediated antibody-dependent cellular cytotoxicity in human immunodeficiency virus type 1 infection. J Virol. 2009;83:8705-12. 
28. Forthal DN, Landucci G, Haubrich R, Keenan B, Kuppermann BD, Tilles JG, Kaplan J. Antibody-dependent cellular cytotoxicity independently predicts survival in severely immunocompromised human immunodeficiency virus-infected patients. J Infect Dis. 1999;180:1338-41.

29. Hessell AJ, Hangartner L, Hunter M, Havenith CE, Beurskens FJ, Bakker JM, Lanigan CM, Landucci G, Forthal DN, Parren PW, et al. Fc receptor but not complement binding is important in antibody protection against HIV. Nature. 2007:449:101-4.

30. Jia M, Li D, He X, Zhao Y, Peng H, Ma P, Hong K, Liang H, Shao Y. Impaired natural killer cell-induced antibody-dependent cell-mediated cytotoxicity is associated with human immunodeficiency virus-1 disease progression. Clin Exp Immunol. 2013;171:107-16.

31. Chung AW, Navis M, Isitman G, Wren L, Silvers J, Amin J, Kent SJ, Stratov I. Activation of NK cells by ADCC antibodies and HIV disease progression. J Acquir Immune Defic Syndr. 2011;58:127-31.

32. Wren LH, Chung AW, Isitman G, Kelleher AD, Parsons MS, Amin J, Cooper DA, Stratov I, Navis M, Kent SJ. Specific antibody-dependent cellular cytotoxicity responses associated with slow progression of HIV infection. Immunology. 2013;138:116-23.

33. Montoya CJ, Velilla PA, Chougnet C, Landay AL, Rugeles MT. Increased IFN-gamma production by NK and CD3 +/CD56+ cells in sexually HIV1-exposed but uninfected individuals. Clin Immunol. 2006;120:138-46.

34. Jiang Y, Cui X, Cui C, Zhang J, Zhou F, Zhang Z, Fu Y, Xu J, Chu Z, Liu J, et al. The function of CD3 + CD56+ NKT-like cells in HIV-infected individuals. Biomed Res Int. 2014;2014:863625.

35. Golden-Mason L, Castelblanco N, O'Farrelly C, Rosen HR. Phenotypic and functional changes of cytotoxic CD56pos natural T cells determine outcome of acute hepatitis C virus infection. J Virol. 2007:81:9292-8.

36. Werner JM, Heller T, Gordon AM, Sheets A, Sherker AH, Kessler E, Bean KS, Stevens M, Schmitt J, Rehermann B. Innate immune responses in hepatitis $C$ virus-exposed healthcare workers who do not develop acute infection. Hepatology. 2013;58:1621-31.
37. Kawano T, Cui J, Koezuka Y, Toura I, Kaneko Y, Motoki K, Ueno H, Nakagawa R, Sato H, Kondo E, et al. CD1d-restricted and TCR-mediated activation of valpha14 NKT cells by glycosylceramides. Science. 1997:278:1626-9.

38. Mise N, Takami M, Suzuki A, Kamata T, Harada K, Hishiki T, Saito T, Terui K, Mitsunaga T, Nakata M, et al. Antibody-dependent cellular cytotoxicity toward neuroblastoma enhanced by activated invariant natural killer T cells. Cancer Sci. 2016;107:233-41.

39. Holtan SG, Creedon DJ, Thompson MA, Nevala WK, Markovic SN. Expansion of CD16-negative natural killer cells in the peripheral blood of patients with metastatic melanoma. Clin Dev Immunol. 2011;2011:316314.

40. Chung AW, Rollman E, Center RJ, Kent SJ, Stratov I. Rapid degranulation of NK cells following activation by HIV-specific antibodies. J Immunol. 2009;182:1202-10.

41. Ljunggren K, Broliden PA, Morfeldt-Manson L, Jondal M, Wahren B. IgG subclass response to HIV in relation to antibody-dependent cellular cytotoxicity at different clinical stages. Clin Exp Immunol. 1988;73:343-7.

42. Niwa R, Natsume A, Uehara A, Wakitani M, lida S, Uchida K, Satoh M, Shitara K. IgG subclass-independent improvement of antibody-dependent cellular cytotoxicity by fucose removal from Asn297-linked oligosaccharides. J Immunol Methods. 2005:306:151-60.

43. Bonsignori M, Pollara J, Moody MA, Alpert MD, Chen X, Hwang KK, Gilbert PB, Huang Y, Gurley TC, Kozink DM, et al. Antibody-dependent cellular cytotoxicity-mediating antibodies from an HIV-1 vaccine efficacy trial target multiple epitopes and preferentially use the $\mathrm{VH} 1$ gene family. J Virol. 2012;86:11521-32.

44. Gomez-Roman VR, Florese RH, Patterson LJ, Peng B, Venzon D, Aldrich K, Robert-Guroff M. A simplified method for the rapid fluorometric assessment of antibody-dependent cell-mediated cytotoxicity. J Immunol Methods. 2006;308:53-67.

\section{Submit your next manuscript to BioMed Central and we will help you at every step:}

- We accept pre-submission inquiries

- Our selector tool helps you to find the most relevant journal

- We provide round the clock customer support

- Convenient online submission

- Thorough peer review

- Inclusion in PubMed and all major indexing services

- Maximum visibility for your research

Submit your manuscript at www.biomedcentral.com/submit
() Biomed Central 